\title{
Performance of a Brazilian sample on the computerized Wisconsin Card Sorting Test
}

\author{
Luzia Flavia Coelho, Maria Conceição do Rosário, Rosana Savio Mastrorosa, Monica Carolina \\ Miranda, Orlando Francisco Amodeo Bueno. \\ Universidade Federal de São Paulo, São Paulo, SP, Brazil
}

\begin{abstract}
The computerized version of the Wisconsin Card Sorting Test (WCST) is based on the same normative data developed previously for the manual version. However, equivalence of the measures of both versions is controversial. This study investigated the performance of a Brazilian student sample with subjects aged 6-15 years in the computerized version of the WCST. As a result of the analyses, the study pointed out that type of school (public or private) was significant in almost all measures and also that age and gender effects were similar to those previously described in the manual version. These results showed that the computerized WCST may not be free of cultural and socioeconomic influences and that the validation and standardization of this version is warranted.
\end{abstract}

Keywords: computerized Wisconsin Card Sorting Test; normative data; children; adolescents; executive functions.

Received 15 November 2012; received in revised form 22 May 2012; accepted 25 May 2012. Available online 28 December 2012.

\section{Introduction}

Executive functions (EFs) may be described as a complex construct that encompasses many cognitive skills and interrelated functions such as anticipation, planning and organization strategies, cognitive flexibility, self-regulation, self-monitoring, inhibition and activity shifting when necessary to generate a new action (Miyake et al., 2000; Gioia, Isquith, Retzlaff \& Espy, 2002; MuñozCéspedes \& Tirapu-Ustarroz, 2004; Weyandt, 2005). Regarding the development of EFs, several authors agree that EFs develop in a progressive nonlinear manner from childhood to adolescence with three stages of maturation: early childhood (6-8 years of age), middle childhood (9-12 years of age), and adolescence (Brocki \& Bohlin, 2004; Shing, Lindenberger, Diamond \& Davidson, 2010).

In addition to the complexity of the definition, several studies have used different tests that may capture various aspects of the EFs (Brocki \& Bohlin, 2004; Gomes, Mattos, Pastura, Ayrão, Saboya, 2005; LopezCampo, Gomez-Betancur, Aguirre-Acevedo, Puerta\& Pineda, 2005; Lawrence et. al., 2004; Borges, Trentini, Bandeira, Dell'aglio, 2008). One of the most popular and widely used tests in neuropsychological assessment of

Luzia Flavia Coelho, Maria Conceição do Rosário, Rosana Savio Mastrorosa, Monica Carolina Miranda, Orlando Francisco Amodeo Bueno. Universidade Federal de São Paulo, SP, Brazil. Correspondence regarding this article should be directed to: Luzia Flavia Coelho - R. Embaú, 54 CEP: 04039060. São Paulo, SP, Brazil. Phone: (55-11) 5549-6899/55495496; FAX: (55-11) 5572-5092; E-mail: flaviacoelho2000@, hotmail.com
EFs is the Wisconsin Card Sorting Test (WCST) (Heaton et al., 1993). The manual version of the WCST was developed by Berg in 1948 as a measure of abstraction and inhibition, mental flexibility, problem solving and categorization (Heaton et al., 1993).

In children and adolescents, the WCST has shown to be important in studies where the main goal is to discriminate clinical from nonclinical cases. The WCST has been widely used to investigate the performance of children with neuropsychiatric disorders such as autism and other pervasive developmental disorders (Ozonoff, 1995; Dawson, Meltzoff, Osterling \& Rinaldi, 1998; Chase-Carmichael, Ris, Weber \& Schefft, 1999; Tsuchiya, Oki, Yahara, \& Fujieda, 2005); and attention deficit hyperactivity disorder (ADHD) (Romine et al., 2004; Lopez-Campo et al., 2005). These studies demonstrated significant differences in the WCST results between case and control children.

Additionally, studies have investigated the association among age, gender, socioeconomic status and the WCST manual version scores. Regarding gender, many studies have reported that it does not affect the results (Chelune \& Baer, 1986; Heaton et al., 1993; Heaton, Chelune, Talley, Kay \& Curtiss, 2005; Rosselli \& Ardila, 1993). Regarding age, studies reported that the performance in the North American samples gradually increased from age 6 years to age 19 years and remained stable after this age (Heaton et al., 2005). Similarly, in the Brazilian normative data study, authors demonstrated that age had a significant association with almost all categories of the manual WCST (Heaton et al., 2005). 
Coffey, Marmol, Schock, and Adams (2005) reinforced the idea that cultural influences affect the performance on the manual version of the WCST and that Mexicans living in the USA had different levels of performances when compared to the USA normative data (Heaton et al., 2005). Contrary to these results, Rosselli and Ardila (1993) reported that socioeconomic status had no effect on the performance of culturally distinct educational groups.

In Brazil, a preliminary study of standardization of the manual version of the WCST showed significant differences according to age and years of education (Heaton et al., 2005). The authors also compared these data with the American norms, and the Brazilian sample had a lower performance on all WCST measures. The authors concluded that these differences could be associated with cultural factors and emphasized the need for studies that could determine the Brazilian norms.

More recently, a computerized version of the WCST was developed and it is currently commercialized (Heaton, 2005). Responses are automatically analyzed by the software, resulting in correction time and reduction in common errors risk (Artiola i Fortuny \& Heaton, 1996; Tien et al., 1996; Feldstein et al., 1999).

So far, this computerized version calculates the scores using the manual version norms developed for the American population. Some studies have been conducted to establish equivalence between the computerized and manual versions of the WCST. Artiola, Fortuny and Heaton (1996) tested both versions in a group of adults $(n$ $=119$ ) and reported that both computerized and manual versions did not differ in regard to any of the measures except trials to complete the first category. However, Feldstein et al. (1999) compared the performance of a sample in the manual version and in the four computerized versions, showing that none of the computerized versions was found to be equivalent to the manual version on all assessment measures.

In studies with children, Shu, Tien, Lung and Chang (2000) evaluated 219 Thai children ranging in ages from 6 to 11 years, using the computerized version in order to develop norms for the Thai population. These authors also compared the results with the manual version norms of the study of Chelune and Baer (1986). This comparison showed significant cultural differences in the measures of completed categories and perseverative errors, with lower scores in the Thai population.

Ozonoff (1995) assessed 24 high-functioning autistic subjects and compared their scores with normal controls matched by age and IQ scores. Half the sample was assessed with the manual version and the other half with the computerized version. Interestingly, the autistic group had a significantly higher performance on the computerized version, reinforcing the relevance of developing specific norms for the computerized version of the WCST.

In summary, studies have consistently shown that certain factors - such as age, socioeconomic status and cultural factors - can affect performance on WCST tests and emphasize the need for the development of norms specific to each population and type of version. In order to fulfill this gap, the current study was developed aimed at the following objectives: a) to determine the performance of Brazilian subjects aged 6 to 15 years on the computerized version of the WCST; b) to analyze the effects of age, gender and socioeconomic status on the performance of the WCST computerized version.

\section{Methods \\ Subjects}

This study was approved by the Ethics Committee of the Federal University of São Paulo. After a detailed description of the study was presented to the subjects, their teachers and parents, all parents signed an informed consent and children signed an informed assent form.

The sample was collected from both public and private schools in order to ensure the inclusion of children and adolescents representative of different socioeconomic status (DalVesco, Mattos, Benincá \& Tarasconi, 1998; Angelini, Alves, Custódio, Duarte \& Duarte, 1999; Ducan, 2006; Shayer, 2007). This research was conducted in two stages:

Stage 1: This study was conducted between 2007 and 2008 with a total participation of 459 children of both genders and aged 6 to 10 years. The criteria to enter the study were to be an odd number in the class presence book and to be a student from the $1^{\text {st }}$ to $4^{\text {th }}$ grade at the elementary level in public and private schools. Parents/guardians had to authorize the child's participation, answer a questionnaire about the child's developmental conditions and complete the Brazilian socioeconomic rating scale (www.abep.org). Next, the Conners Abbreviated Questionnaire-CATRS-10 (Brito, 1987) and the Human Figure Drawing Test (HFD) (Wechsler, 2003) were applied to evaluate the child's cognitive development.

Stage 2: This stage was conducted between 2008 and 2009 with a total participation of 821 school-age children of both genders and aged 11 to 15 years. A random selection of classrooms using a lottery system in public and private high schools was conducted. Parents/guardians had to authorize the child's participation, answer a questionnaire about the child's developmental conditions and complete the Brazilian socioeconomic rating scale (www.abep.org). The screening instruments applied were the CATRS-10 questionnaire and the reduced WISC-III to obtain Estimated IQ (Mello et al., 2011).

Inclusion criteria were that the participants should be 6 to 17 years old with an IQ $\geq 80$. They should present no symptoms of mental disorders that could interfere with the performance on the tests such as epilepsy, dyslexia, learning disabilities or ADHD.

Exclusion criteria were presence of any symptoms of any clinical or psychiatric disorders, IQ $<80$, not signing the informed consent or assent forms. During Stage 1,59 children were excluded due to the following reasons: 13 presented a high risk of having medical problems according to the "Medical History Screening 
Questionnaire"; 33 scored on Conners rating scale above the cut-off point; and 13 showed low performances on the Wechsler Drawing of the Human Figure subtest.

During Stage 2, 23 subjects were excluded due to the presence of some symptoms included in the Medical History Questionnaire; 11 were excluded because of IQ scores $<80$; and 41 subjects were excluded because of CATRS-10 scores above the cut-off point.

Together the final sample was comprised of 1,146 children and adolescents between 6 and 15 years of age.

\section{Instruments and procedures}

(a) Socioeconomic rating scale-developed by the Brazilian Association of Companies and Research, ABEP (www.abep.org). This scale assesses the level of education of the person responsible for the family's primary source of income and a total score on household comfort items.

(b) Medical history questionnaire-this questionnaire was developed by the study researchers in order to investigate the history of lifetime or current medical disorders including epilepsy, head trauma, and neurological and psychiatric disorders.

(c) Conners abbreviated scale (CATRS-10) - this is a 10-item scale developed to assess attention and hyperactivity symptoms. It has been validated for the Brazilian population and has been widely used as a screening instrument (Brito, 1987).

(d) Wechsler Intelligence Scale for Children (WISC-III) - a widely used instrument for assessing intelligence scores in subjects aged 6 to 16 years and 11 months (Wechsler, 2002).

(e) Human Figure Drawing (HFD) - evaluates the intellectual level through a drawing of a person (Wechsler, 2003).

After assessing all subjects with the instruments above, the WCST was applied. The WCST version used in this study was the Psychological Assessment Resources computerized version of the Wisconsin Card
Sorting Test 4 (Heaton, 2005). The test was carried out exactly as described in the instruction booklet. Subjects were tested individually at the school they attended, in appropriate rooms with conditions appropriate for sound and lighting. The test was presented on a laptop computer, and the total mean application time was $\sim 30$ min for each evaluation.

\section{Statistical analysis}

WCST raw scores were analyzed in all test measures: trials administered, total number of correct responses, total and percentage of errors, perseverative responses, perseverative errors, nonperseverative errors, conceptual level responses, categories completed, trials to complete first category, and failure to maintain the set.

Demographic data such as gender, age, IQ scores and type of school (public or private) were analyzed using the categorical chi-square test.

The hypothesis of normal distribution and equality of variances were checked using the Levene Test. To verify the interactions among three fixed variables (age, gender and type of school), ANOVA was used. The least significant difference (LSD) was applied with multiple comparisons. IQ scores were analyzed as a co-variable in order to verify the effect of that measure in the performance concerning gender, age and type of school.

In all analyses a significance level of $5 \%$ was adopted; SPSS statistical software version 13.0 was used.

\section{Results}

The final sample of 1,146 students was composed of 615 girls and 531 boys. A total of 592 students attended public and 554 attended private schools.

The analysis of gender proportion in different age groups, considering the type of school, showed no significant differences $\left(\chi^{2}=1.384, p=0.239\right)$. The proportion of children in public schools was significantly lower only at the age of 10 years $(p=0.04)$.

Table 1. Distribution of the subjects according to age, gender and type of school

\begin{tabular}{|c|c|c|c|c|c|}
\hline \multirow[b]{2}{*}{ Age group (years) } & \multirow{2}{*}{$\frac{\text { Total sample }}{(n)}$} & \multicolumn{2}{|c|}{ Private school } & \multicolumn{2}{|c|}{ Public school } \\
\hline & & Female (n) & Male (n) & Female $(n)$ & Male (n) \\
\hline 6.5 & 58 & 16 & 16 & 17 & 9 \\
\hline 7 & 93 & 17 & 18 & 26 & 32 \\
\hline 8 & 91 & 23 & 18 & 29 & 21 \\
\hline 9 & 91 & 21 & 23 & 25 & 22 \\
\hline 10 & 64 & 20 & 19 & 10 & 15 \\
\hline 11 & 172 & 43 & 40 & 52 & 37 \\
\hline 12 & 159 & 42 & 33 & 46 & 38 \\
\hline 13 & 157 & 38 & 34 & 52 & 33 \\
\hline 14 & 138 & 42 & 31 & 33 & 32 \\
\hline 15 & 123 & 32 & 28 & 31 & 32 \\
\hline TOTAL & 1146 & 294 & 260 & 321 & 271 \\
\hline
\end{tabular}


There were significant differences in IQ levels according to the type of school, and students from public schools had significantly lower IQ scores $(p=$ $0.001)$. At the private schools, $70 \%$ of the sample had an IQ $>110$, whereas only $52 \%$ of students from public schools reached these IQ levels.

There were no significant effects of the three-way interaction (gender, age and school) in any of the WCST measures (Wilks lambda $=0.894, \mathrm{~F}[135.8503]=0.916$, $p=0.747)$ or interaction between gender and school (Wilks lambda $=0.990, \mathrm{~F}[15.1091]=0.721, p=0.765$ ), gender and age (Wilks lambda $=0.895, \mathrm{~F}(135.8503$ ] $=$ $0.903, p=0.783)$. There was interaction between school and age $($ Wilks lambda $=0.840, \mathrm{~F}[135.8503]=1.426, p$ $=0.001)$. Finally, gender had no significant effect on the WCST measures (Wilks lambda $=0.991, \mathrm{~F}[15.1091]=$ $0.686, p=0.801)$.

Analysis of the interaction between type of school and age showed significant differences in all measures, except for failure to maintain the set (please refer to Table 3 for significance values). At measures of trials administered at ages 13,14, and 15, public school children required a greater number of cards to complete the test (being a lower performance). At measures of correct responses, a difference was noted at ages 11 and 12 years, and public school children showed the lowest performance. At measures of errors (total and percent) at ages 11 to 15 years, public school children presented a lower performance. At measures of perseverative responses (total and percent) and perseverative errors (total and percent) at a mean age of 6 years, public school children showed a higher performance than children attending private schools but, at ages 11,12 , 14 and 15 years, public school children showed lower scores than the children attending private schools. At measures of nonperseverative errors (total and percent), at the age of 7 years, public school children outperformed children attending private schools, but at ages 11, 13, 14 and 15 years, performance of children attending public schools was lower than the performance of children attending private schools. At measures of conceptual level responses at ages 11,12 and 14 years, public school children had the lowest performance. At measures of percent conceptual level responses at ages 11 to 15 years, public school children presented the lowest performance as well. At measures of categories completed at a mean age of 6 years, public school children outperformed children attending private schools, but at ages 11 to 15 years, public school children had lower scores. At measures of trials to complete first category at an average age of 6.5 to 9 years, public school children had a higher performance.

When analyses were done using IQ as a covariate, the effects of age and type of school in the WCST scores remained significant, independently of subjects' IQ (Wilks lambda $=0.945, \mathrm{~F}[15.1113]=4,334, p=0.001$ ).

\section{Discussion}

The aim of this study was to assess the performance of Brazilian subjects aged 6 to 15 years using the computerized version of the WCST and to analyze possible effects of age, gender and socioeconomic status on their performance. Some studies in the literature have already analyzed the manual version of the test (Chelune \& Baer, 1986; Heaton et al. 1993; Rosselli \& Ardila 1993; Heaton et al., 2005), and fewer analyzed the computerized version (Artioli i Fortuny \& Heaton, 1996; Feldstein et al. 1999; Shu et al., 2000). This is the first study to analyze the computerized version of the WCST in Brazil.

The current study showed that there were significant differences in IQ scores between students from public and private schools. The results were similar to other IQ studies in the Brazilian population (DalVesco et al., 1998; Shayer, 2007), which confirm that some intellectual ability measures may be vulnerable to cultural patterns, favoring children of a higher socioeconomic status.

Regarding IQ, $\sim 15 \%$ of children attending private schools and $9 \%$ of public school children have an estimated IQ of 130 and above and this could be considered as a relatively high proportion of children with a high IQ. Even though it can be argued that the study sample may not represent the primary population of children aged 6 to 15 years, it is important to mention that the scores on the computerized version of the WCST were not affected by IQ scores.

Table 2. Distribution of the subjects according to IQ

\begin{tabular}{|c|c|c|c|c|c|c|}
\hline \multirow{3}{*}{ Classification } & \multicolumn{6}{|c|}{ Estimated IQ } \\
\hline & \multicolumn{2}{|c|}{ Total $(n=1146)$} & \multicolumn{2}{|c|}{ Private school $(n=554)$} & \multicolumn{2}{|c|}{ Public school $(n=592)$} \\
\hline & $\mathbf{N}$ & $\%$ & $\mathbf{N}$ & $\%$ & $\mathbf{N}$ & $\%$ \\
\hline Low average (80-89) & 51 & 4 & 7 & 1 & 44 & 7 \\
\hline Average (90-109) & 402 & 35 & 164 & 30 & 238 & 40 \\
\hline Above average (110-119) & 289 & 25 & 147 & 27 & 142 & 24 \\
\hline Superior (120-129) & 269 & 23 & 155 & 28 & 114 & 19 \\
\hline Very superior $(>130)$ & 135 & 12 & 81 & 15 & 54 & 9 \\
\hline
\end{tabular}


Table 3. Age, gender, school and interaction effects on WCST measures

\begin{tabular}{|c|c|c|c|c|c|c|c|c|c|c|c|c|}
\hline \multirow[t]{2}{*}{ WCST measure } & \multicolumn{3}{|c|}{ Age } & \multicolumn{3}{|c|}{ Gender } & \multicolumn{3}{|c|}{ School } & \multicolumn{3}{|c|}{ Age $x$ School } \\
\hline & $\mathbf{F}$ & $p$ & $\begin{array}{c}\text { Effect } \\
\text { size }\end{array}$ & $\mathbf{F}$ & $p$ & $\begin{array}{c}\text { Effect } \\
\text { size }\end{array}$ & $\mathbf{F}$ & $p$ & $\begin{array}{c}\text { Effect } \\
\text { size }\end{array}$ & $\mathbf{F}$ & $p$ & $\begin{array}{c}\text { Effect } \\
\text { size }\end{array}$ \\
\hline Trials administered & 20.617 & 0.000 & 0.142 & 2.367 & 0.124 & 0.002 & 15.806 & 0.000 & 0.014 & 5.951 & 0.000 & 0.045 \\
\hline Correct responses & 9.613 & 0.000 & 0.071 & 1.216 & 0.270 & 0.001 & .898 & 0.344 & 0.001 & 3.038 & 0.001 & 0.024 \\
\hline Total errors & 21.734 & 0.000 & 0.148 & 3.221 & 0.073 & 0.003 & 10.122 & 0.002 & 0.009 & 4.114 & 0.000 & 0.032 \\
\hline$\%$ Errors & 20.925 & 0.000 & 0.143 & 2.806 & 0.094 & 0.002 & 9.652 & 0.002 & 0.009 & 4.096 & 0.000 & 0.032 \\
\hline Perseverative responses & 14.345 & 0.000 & 0.103 & 5.218 & 0.023 & 0.005 & 4.299 & 0.038 & 0.004 & 3.756 & 0.000 & 0.029 \\
\hline$\%$ Perseverative responses & 12.620 & 0.000 & 0.092 & 4.699 & 0.030 & 0.004 & 3.268 & 0.071 & 0.003 & 3.630 & 0.000 & 0.028 \\
\hline Perseverative errors & 14.220 & 0.000 & 0.102 & 6.205 & 0.013 & 0.005 & 5.094 & 0.024 & 0.005 & 3.892 & 0.000 & 0.030 \\
\hline$\%$ Perseverative errors & 12.386 & 0.000 & 0.090 & 5.598 & 0.018 & 0.005 & 3.751 & 0.053 & 0.003 & 3.678 & 0.000 & 0.029 \\
\hline Nonperseverative errors & 9.841 & 0.000 & 0.073 & 0.033 & 0.856 & 0.000 & 5.924 & 0.015 & 0.005 & 2.620 & 0.005 & 0.021 \\
\hline$\%$ Nonperseverative errors & 8.427 & 0.000 & 0.063 & .001 & 0.969 & 0.000 & 5.314 & 0.021 & 0.005 & 2.419 & 0.010 & 0.019 \\
\hline Conceptual level responses & 12.776 & 0.000 & 0.093 & 2.032 & 0.154 & 0.002 & 2.959 & 0.086 & 0.003 & 3.111 & 0.001 & 0.024 \\
\hline$\%$ Conceptual level responses & 20.134 & 0.000 & 0.139 & 3.019 & 0.083 & 0.003 & 9.708 & 0.002 & 0.009 & 3.902 & 0.000 & 0.030 \\
\hline Categories completed & 17.720 & 0.000 & 0.124 & 3.332 & 0.068 & 0.003 & 4.947 & 0.026 & 0.004 & 5.049 & 0.000 & 0.039 \\
\hline Trials to complete first category & 3.896 & 0.000 & 0.030 & 1.480 & 0.224 & 0.001 & 17.022 & 0.000 & 0.015 & 3.761 & 0.000 & 0.029 \\
\hline Failure to maintain set & 1.559 & 0.123 & 0.012 & .358 & 0.550 & 0.000 & .817 & 0.366 & 0.001 & 0.380 & 0.945 & 0.193 \\
\hline
\end{tabular}

Regarding the analyses of effects concerning age, gender and type of school in the current study sample, in all measures of the WCST computerized version, we observed that gender effect was not significant, thus showing results similar to those found in previous studies with the manual version of the test (Chelune \& Baer, 1986; Heaton et al., 1993; Rosselli \& Ardila, 1993; Heaton et al., 2005) and with the computerized version in children (Shu et al., 2000).

Moreover, there was no interaction with age, gender and school type; gender and school; gender and age. Shu et al. (2000) did not report whether the interaction analysis was performed with these variables, making it difficult to compare with the current results.

Regarding the effects of type of school and age, the performance increases with age and this fact has already been pointed out in the norms of the American population manual version of the test. WCST manual norms did not describe in detail the association between age and the scores of the WCST but showed the curve regression for age, which revealed a substantially increased proficiency in the performance of the WCST from ages 6 to 19 years. From this age on, the results remained quite stable at the ages of 20,30, 40 and 50 years (Heaton et al., 2005). Similarly, in the Brazilian normative sample of the manual version, the authors reported age as a significant variable in almost all categories of the WCST (Heaton et al., 2005), but they did not describe in detail what measures presented such differences and what the performance standard was at different ages. In the current study it was observed that in a narrower age range with a difference of only 1 year, there were no significant results, but comparing age groups with more than 2 years of difference, there are more significant differences, especially in the younger age groups. As the age increases, the differences become less and at the age of 13 the performance becomes similar to the older age groups, corroborating the hypotheses that were investigated in studies of the development of EFs (Brock \& Bohlin, 2004; Shayer, 2007).

Additionally, these changes in performance according to age were also influenced by socioeconomic status. The results of this study showed that private school students had a higher performance in all significant variables. However, it is important to point out that such differences appeared in older age groups starting at the age of 11 years, probably due to the fact that at this age the major maturity of the EFs occurs and thus the influence of the environment becomes more evident, as suggested in the literature (Brocki \& Bohlin, 2004). This may explain the higher performance of the 6- and 7-year-old group of students on the measures of perseverative response and errors and nonperseverative errors, respectively. It is interesting to mention that public school children 6- to 7-years of age had a higher performance compared to children attending private schools of the same two age groups. At age 8 years and above, however, this effect was inverted and public school children had a lower performance in comparison with children attending private schools. Despite this 


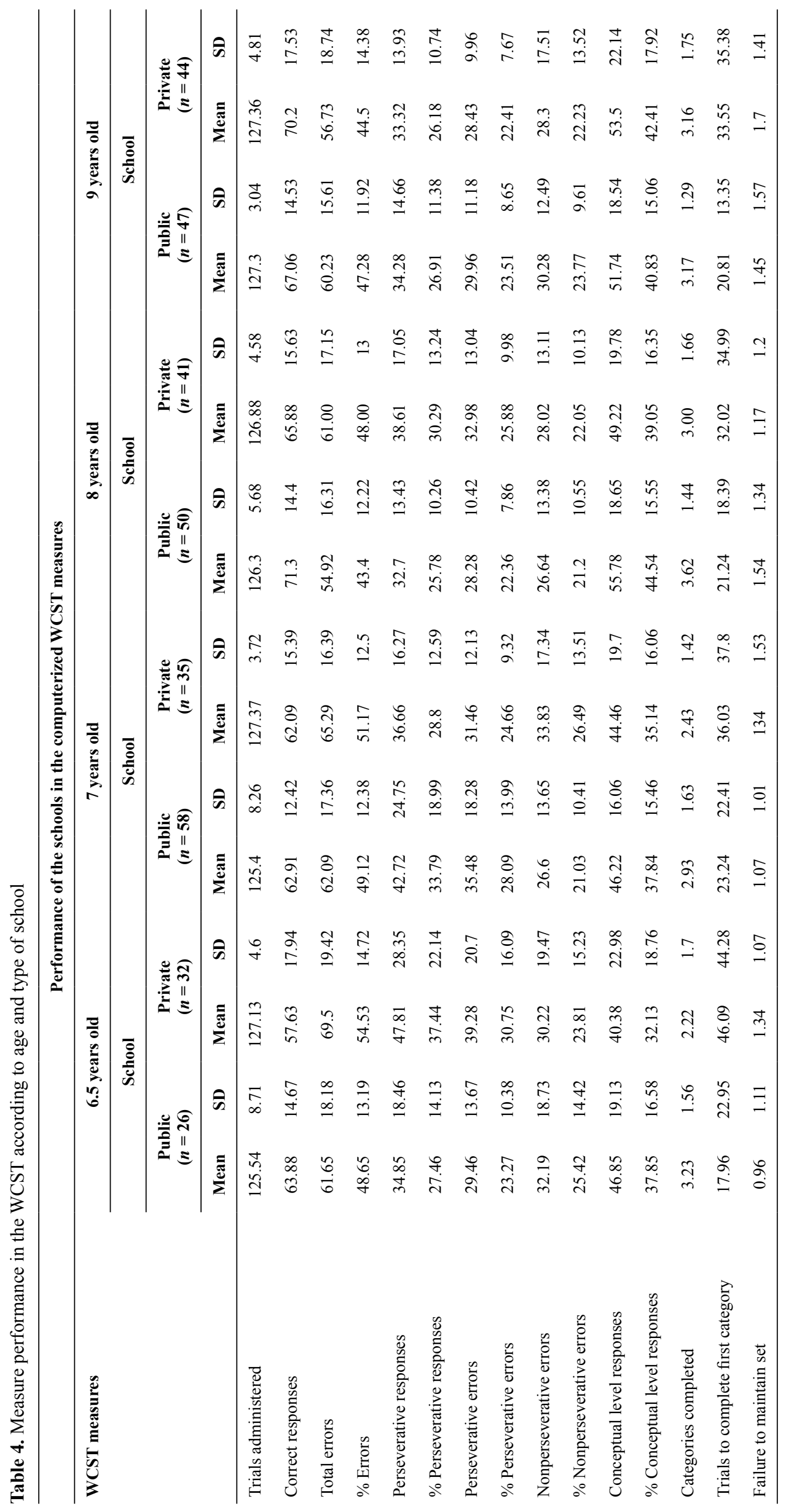




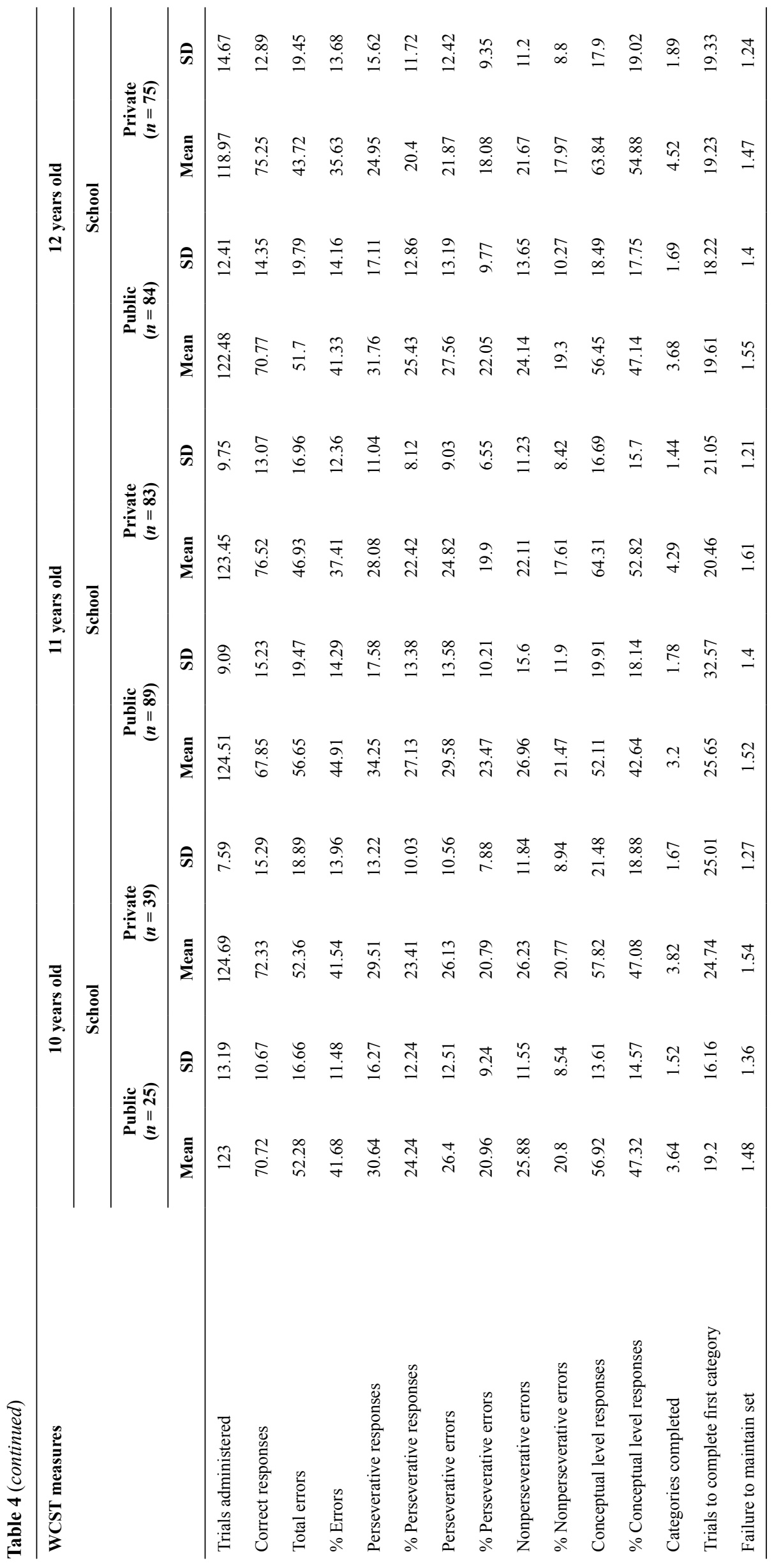




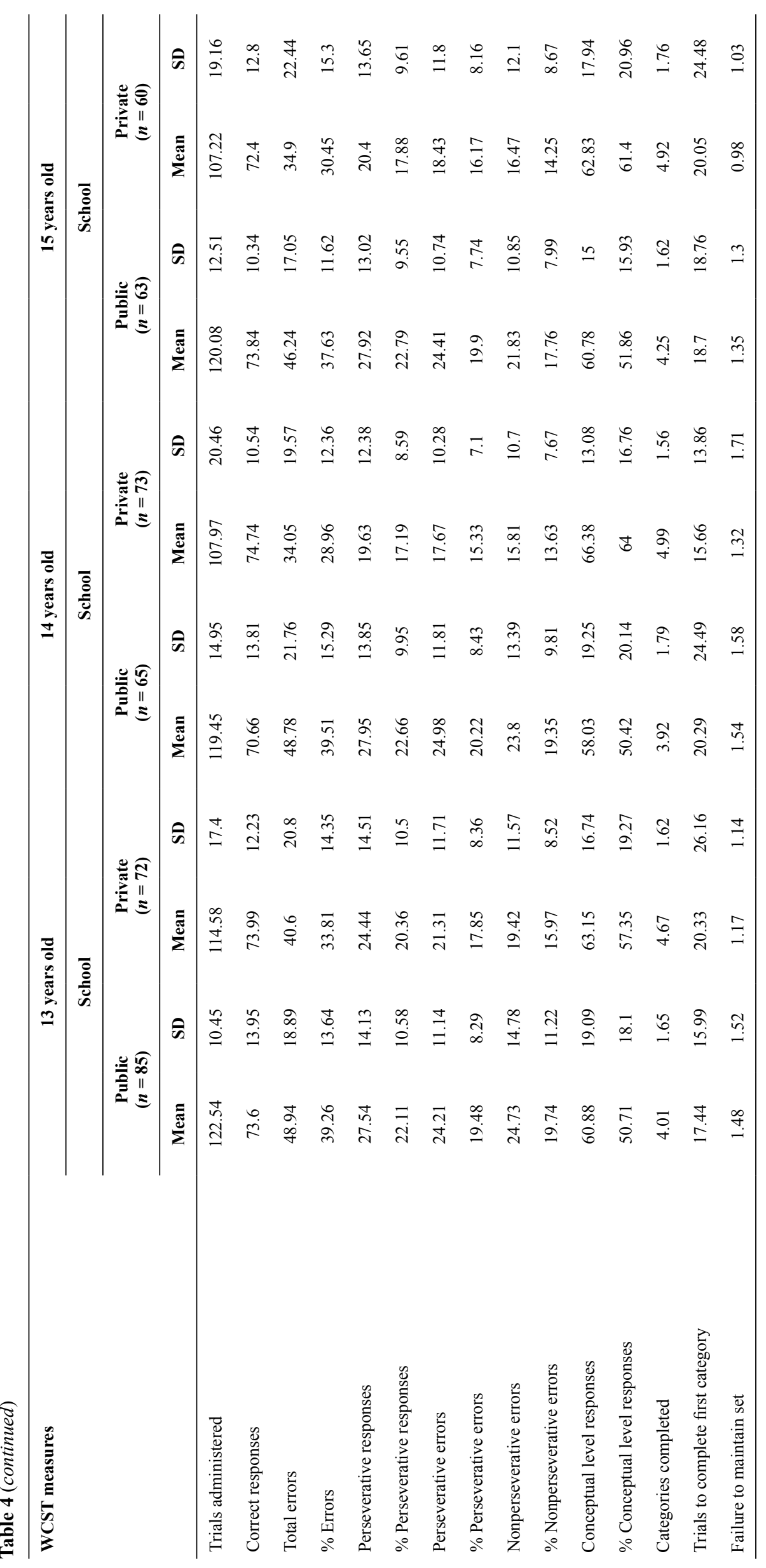


interesting finding, the current study was not designed to investigate this.

The fact that the type of school influenced the WCST measures reinforces the hypothesis that socioeconomic status influences test performance, which has been shown by other studies, although the methods vary considerably. For example, in the study by Rosselli and Ardila (1993), Colombian participants belonged to low and high socioeconomic status in the two schools selected for each level. The authors found an interaction between socioeconomic status and age, but only in the nonperseverative errors. The authors mentioned that the differences were evident in the younger group and disappeared when age and socioeconomic group level increased. Shu et al. (2000) analyzed the effects of various factors on the performance of WCST using variables such as parental education, occupation, number of siblings, mother's age during pregnancy and birth weight of the child. The only significant effect was parental education on the following: "total correct letters," "categories completed," "conceptual level," "perseverative error" and "perseverative response."

The study of norms for the WCST manual version for the Brazilian population (Heaton et al., 2005) did not assess participants' performance considering the type of school because the sample was composed only of children attending public schools, so comparisons are not possible with the current study.

Other Brazilian studies that examined the influence of school type on the performance of neuropsychological tests reported the influence of socioeconomic level. Duncan (2006) noted that private school students had a higher performance on time measures of the Stroop test in comparison with students from public schools. Shayer (2007) also pointed out that at measures of visual attention and EFs of the NEPSY-I, students in public schools had the lowest scores.

In summary, the literature emphasizes that, in addition to the specific norms for each population, the norms for the different versions of the tests (either manual or computerized) are also relevant as several studies comparing the two versions are controversial, i.e., some authors found them equivalent (Hellman, Green, Kern \& Christenson, 1992; Artiola i Fortuny \& Heaton, 1996; Feldstein et al., 1999) and others did not (Tien et al., 1996; Shu et al., 2000).

In a new digital age when there has been a tendency to use computers for neuropsychological tests, we should pay attention to the effects on the subjects' performance analysis. Thus, validity and normative studies for each population where the WCST will be applied are necessary for a better understanding of the results.

The current study adds important information to the literature on the WCST. A significantly large sample of school-age children and adolescents were interviewed by highly trained professionals, and the findings reinforce the influence of socioeconomic level on the results of the computerized version of the WCST.

\section{References}

Angelini, A. L., Alves, I. C. B., Custódio, E. M., Duarte, W. F., \& Duarte, J. L. M. (1999). Manual: Matrizes Progressivas de Raven. São Paulo: Centro Editor de Testes e Pesquisa em Psicologia.

Artiola i Fortuny, L., \& Heaton, R. K. (1996). Standard versus computerized administration of the Wisconsin card sorting test. The Clinical Neuropsychologist, 10(4), 419-424.

Borges, J. L., Trentini, C. M., Bandeira, D. R., \& Dell'aglio, D. D. (2008). Avaliação neuropsicológica dos transtornos psicológicos na infância: Um estudo de revisão. Psico-USF, 13(1), 125-133.

Brito, G. N. O. (1987). The Conners abbreviated teacher rating scale: Development of norms in Brazil. Journal of Abnormal Child Psychology, 15(4), 511-518.

Brocki, K. C., \& Bohlin, G. (2004). Executive functions in children aged 6 to 13: A dimensional and developmental study. Developmental Neuropsychology, 26(2), 571-593.

Chase-Carmichael, C. A., Ris, M. D., Weber, A. M., \& Schefft, B. K. (1999). Neurologic validity of the Wisconsin card sorting test with a pediatric population. The Clinical Neuropsychologist, 13(4), 405-413.

Chelune, G. J., \& Baer, R. A. (1986). Developmental norms for the Wisconsin Card Sorting Test. Journal of Clinical and Experimental Neuropsychology, 8, 219-228.

Coffey, D. M., Marmol, L., Schock, L., \& Adams, W. (2005). The influence of acculturation on the Wisconsin Card Sorting Test by Mexican Americans. Archives of Clinical Neuropsychology, 20(6), 795-803.

DalVesco, A., Mattos, D. Benincá, C., \& Tarasconi, C. (1998). Correlação entre WISC e rendimento escolar na escola pública e na escola particular. Psicologia: Reflexão e Critica, 11(3), 481-495.

Dawson, G., Meltzoff, A. N., Osterling, J., \& Rinaldi J. (1998). Neuropsychological correlates of early symptoms of autism. Child Development, 69(5), 1276-1285.

Duncan, M. T. (2006). Obtenção de dados normativos para desempenho no teste de Stroop num grupo de estudantes do ensino fundamental em Niterói. Jornal Brasileiro de Psiquiatria, 55(1), 42-48.

Feldstein, S. N., Keller, F. R., Portman, R. E., Durham, R. L., Klebe, K. J., \& Davis, H. P. (1999). A comparison of computerized and standard versions of the Wisconsin Card Sorting Test. The Clinical Neuropsychologist, 13(3), 303-313.

Gioia, G. A., Isquith, P. K., Retzlaff, P. D., \& Espy, K. A. (2002). Confirmatory factor analysis of the Behavior Rating Inventory of Executive Function (BRIEF) in a clinical sample. Child Neuropsychology, 8(4),249-257.

Gomes, F., Mattos, P., Pastura, G., Ayrão, V., \& Saboya, E. (2005). Executive functions in a non-clinical sample of children and adolescents with attention-deficit hyperactivity disorder (ADHD). Jornal Brasileiro de Psiquiatria, 54(3),178-181.

Heaton, R. K., Chelune, G. J., Talley, J. L., Kay, G. G., Gary, C., \& Curtiss, G. (1993). Wisconsin Card Sorting Test Manual-Revised and Expanded. Odessa: Psychological Assessment Resources.

Heaton, R. K., Chelune, G. J., Talley, J. L., Kay, G. G., \& Curtiss, G. (2005). Manual do Teste Wisconsin de Classificação de Cartas. Adaptação e padronização brasileira. Cunha, J. A. et al. São Paulo: Casa do Psicólogo.

Heaton, R. K. (2005). Wisconsin Card Sorting Test: Computer Version 4 Research Edition. Odessa: Psychological Assessment Resources.

Hellman, S. G., Green, M. F., Kern, R. S., \& Christenson, C. D. (1992). Comparison of card and computer versions of the Wisconsin Card Sorting Test for psychotic patients. International Journal of Methods in Psychiatric Research, 2, 151-155.

Lawrence, V., Houghton, S., Graham, D., Durkin, K., Whiting, K., \& Tannock, R. (2004). Executive function and ADHD: A comparison of children's performance during neuropsychological testing and real-world activities. Journal of Attention Disorders, 7(3), 137-149.

Lopez-Campo, G. X., Gomez-Betancur, L. A., Aguirre-Acevedo, D. C., Puerta, I. C., \& Pineda, D. A. (2005). Attention and executive function tests components in attention deficit/hyperactivity children. Revista de Neurología, 40(6), 331-339.

Mello, C. B., Argollo, N., Shayer, B. P. M., Abreu, N., Godinho, K., Duran, P., ... Bueno, O. F. A. (2011). Versão Abreviada do WISC-III: Correlação entre QI Estimado e QI Total em Crianças Brasileiras. Psicologia: Teoria e Pesquisa, 27(2), 149-155.

Miyake, A., Friedman, N. P., Emerson, M. J., Witzki, A. H., Howerter, A., \& Wager, T.D. (2000). The unity and diversity of executive 
functions and their contributions to complex "frontal lobe" tasks: A latent variable analysis. Cognitive Psychology, 41(1), 49-100.

Muñoz-Céspedes, J. M., \& Tirapu-Ustárroz, J. (2004). Rehabilitación de las funciones ejecutivas. Revista de Neurología, 38(7), 656663.

Ozonoff, S. (1995). Reliability and validity of the Wisconsin card sorting test in studies of autism. Neuropsychology, 9(4), 491-500.

Romine, C. B., Lee, D., Wolfe, M. E., Homack, S., George, C., \& Riccio, C. A. (2004). Wisconsin Card Sorting Test with children: A meta-analytic study of sensitivity and specificity. Archives of Clinical Neuropsychology, 19(8), 1027-1041.

Rosselli, M., \& Ardila, A. (1993). Developmental norms for the Wisconsin Card Sorting Test in 5 to 12 year-old children. The Clinical Neuropsychologist, 7(2), 145-154.

Shayer, B. P. M. (2007). Perfil de desempenho de escolares nas funções cognitivas atenção e funções executivas: Um estudo exploratório na cidade de Salvador-BA. Tese de Doutorado, Universidade de Brasília.

Shing, Y. L., Lindenberger, U., Diamond, A., Li, S. C., \& Davidson, M. C. (2010). Memory maintenance and inhibitory control differentiate from early childhood to adolescence. Developmental Neuropsychology, 35(6), 679-697.

Shu, B. C., Tien, A. Y., Lung, F. W., \& Chang, Y. Y. (2000). Norms for the Wisconsin Card Sorting Test in 6- to 11-year-old children in Taiwan. The Clinical Neuropsychologist, 14(3), 275-286.

Tien, A. Y., Spevack, T. V., Jones, D. W., Pearlson, G. D., Schlaepfer, T. E., \& Strauss, M.E. (1996). Computerized Wisconsin Card Sorting Test: Comparison with manual administration. Kaohsiung Journal of Medical Sciences, 12(8), 479-485.

Tsuchiya, E., Oki, J., Yahara, N., \& Fujieda, K. (2005). Computerized version of the Wisconsin card sorting test in children with highfunctioning autistic disorder or attention-deficit/hyperactivity disorder. Brain \& Development, 27(3), 233-236.

Wechsler, D. (2002). Escala de Inteligência Wechsler para Crianças. $3^{\circ}$ ed. São Paulo: Casa do Psicólogo.

Wechsler, S. (2003). O Desenho da Figura Humana-Avaliação do desenvolvimento cognitivo infantil. $3^{\circ}$ ed. São Paulo: Vetor.

Weyandt, L. L. (2005). Executive function in children, adolescents, and adults with attention deficit hyperactivity disorder: Introduction to the special issue. Developmental Neuropsychology, 27(1), 1-10. 